tumour-specific cytolytic cells are generated. Whether this will eventually represent a turning point in the war against cancer, or whether it is yet another false dawn, considerably more work still needs to be done. But at least the initial battle-plans look hopeful, and there is reason for optimism.

Ian Hart is in the Division of Oncology, United Medical Schools of Guy's and St Thomas' Hospitals, London SE1 7EH, UK. Camilo Colaco is at Quadrant Healthcare, Maris Lane, Cambridge CB2 2SY, UK.
Bailar J. C \& Gornik H. L N. Engl J Med 336, 1569-1574 (1997).

2. Gong, J., Chen, D., Kashiwaba, M. \& Kufe, D. Nature Med. 3, 558-561 (1997).

3. Vlasveld, L.T.\&Rankin,E. M.Cancer Treat. Rev. 20, 275-311 (1994).

4. Pardoll, D. M. Curr. Opin. Immunol. 5, 705-706 (1993).

5. Marland, G. et al. Stem Cells 14, 501-503 (1996)

6. Young, J. W. \& Inaba, K. J. Exp. Med. 183, 7-11 (1996).

7. Flamand, V. et al. Eur. J. Immunol. 24, 605-610 (1994).

8. Boczkowski, D. et al. J. Exp. Med. 184, 465-472 (1996).

9. Guo, Y. et al. Science 263, 518-520 (1994).

10. Bakkar, A. B. H. et al. Cancer Res. 55, 5330-5334 (1995).

11. Matzinger, P. Annu. Rev. Immunol. 12, 991-1045 (1994).

12. Ridge, J. P. et al. Science 271, 1723-1726 (1996).

Biodiversity

\title{
Global change through invasion
}

\section{Gábor L. Lövei}

nvasion by plants and animals occurs everywhere, and has profoundly influenced the shape of the world's biota over geological time. From the very early stages of agriculture, humans have also intentionally transported crops and animals to other regions of the world, thus greatly advancing the material culture of different societies ${ }^{1}$; the introduction of many more organisms was not so welcome. Today, the scale of species introduction by humans is vastly increased. Vitousek et al., in a paper in the New Zealand Journal of Ecology $y^{2}$, argue that species introductions should be recognized as an important component of human-induced global change and as a serious threat to biodiversity.

Invading plant and animal species have caused drastic changes in the receiving biota of islands like New Zealand or Hawaii, as testified by their recent history. Vitousek et al.'s carefully constructed, extensive list of plant invasions now allows us to look at this phenomenon from a more global perspective. Introduced species make up 26-40 per cent of all plant species in isolated regions (Table 1), and even more on islands: for example, 82 per cent of Ascension Island's biota is composed of introduced species. Regions with a high volume of trade generally have more introduced species than less frequented areas. What is surprising, though, is that continental areas are no exceptions. Introduced species make a significant contribution both in terms of the number of species per unit area and as their relative share in the flora (Table 1). There are some striking examples for vertebrates too: New Zealand's fish fauna contains 30 'exotic' species ( 53 per cent of the total), Puerto Rico's has a whopping 91 per cent, and even Brazil has 13 per cent ${ }^{2}$.

Invaders frequently make a heavy impact. The eastern North American deciduous forests have suffered larger perturbations by invading pests and pathogens than from pollution or acid rain $^{3}$. The long-term global effects of invasions are also significant, in two ways. First, they decrease the distinctiveness of local floras and faunas. New Zealand today has more vertebrate species than at the time of human colonization about 1,000 years ago $^{4}$. Even if the extinctions are not considered (all but one of the 50 extinct species were endemic to New Zealand), only one of the introduced species, the Australian parma wallaby (Macropus parma), is threatened in its homeland ${ }^{5}$. So although New Zealand has become more 'diverse', it has also become more similar to the rest of the world. Second, geographic isolation is necessary for the maintenance of global biodiversity. For example, the area of a continent and the number of mammal species it supports show a tight correlation (Fig. 1). If all the Earth's dryland area formed one supercontinent, the predicted global total would be only about half of the actual global species richness (Fig. 1). Similar relationships have been found for several other groups of

\begin{tabular}{|c|c|c|c|c|}
\hline \multirow[t]{2}{*}{ Region/country } & \multicolumn{2}{|c|}{ Number of species } & \multirow[b]{2}{*}{ Exotic/(log) area } & \multirow[t]{2}{*}{ Percentage of exotics } \\
\hline & Native & Exotic & & \\
\hline Russian Arctic & 1,403 & 104 & 15.9 & 6.9 \\
\hline Europe & 11,820 & 721 & 102.8 & 5.7 \\
\hline United States & 17,300 & 2,100 & 304.6 & 10.8 \\
\hline Southern Africa & 20,573 & 824 & 128.1 & 3.9 \\
\hline Australia & 15,638 & 1,952 & 283.5 & 11.1 \\
\hline Ontario & 2,056 & 805 & 133.5 & 28.1 \\
\hline New York state & 1,940 & 1,083 & 210.7 & 35.8 \\
\hline Perth region, Australia & 1,510 & 547 & 136.1 & 26.6 \\
\hline British Isles & 1,255 & 945 & 175.4 & 42.9 \\
\hline Hawaii & 1,143 & 891 & 210.9 & 43.8 \\
\hline New Zealand & 2,449 & 1,623 & 298.9 & 39.9 \\
\hline
\end{tabular}

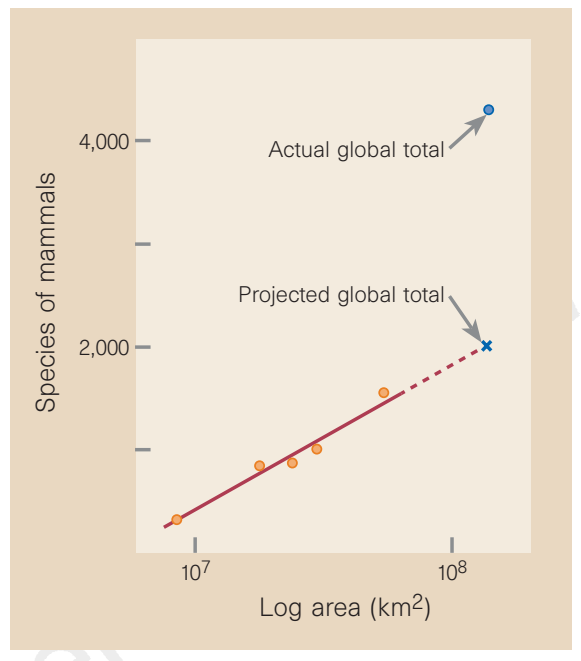

Figure 1 Species versus area curve for mammals. The number of species on a continent is tightly correlated with the size of the continent, but extrapolating that relation to the land area of Earth yields less than half the total number of species that actually occur on these continents. Much of the global diversity of mammalian species is due to the isolation of separate biotic regions. (Analysis prepared by A. Launer. Reproduced from ref. 2.)

organisms $^{6}$. The current human-assisted massive invasions could, in fact, create one 'supercontinent', and with the geographical barriers broken down, the inevitable result would be a catastrophic loss of biodiversity.

Why have species introductions not been recognized as a global phenomenon? Acknowledged components of global change, like ozone depletion or carbon dioxide enrichment (the 'greenhouse effect'), occur on a very large spatial scale and simultaneously affect several different ecosystems. In contrast, invasions are mostly local, and involve a few species acting over a relatively short time frame. A more cohesive view was called for in order to demonstrate that although the players and the location of the ecological 'theatres' may be different, the same 'evolutionary play' is being continuously enacted all over the world. And we constantly busy ourselves with transporting the players from one theatre to another.

Possibly, because natural invasions are going on all the time, just like species extinctions, it was conceptually difficult to recognize the global implications. Species extinction is a problem not because it is a new phenomenon, but because its rate far exceeds the rate of speciation. Likewise, human-assisted invasions are effectively breaking down biogeographical barriers, and the resulting global mixing renders idle one of the most prolific means of generating biodiversity: isolation. If we cannot stop this Macdonaldization of the biosphere, we stand to lose a substantial part of global biodiversity and may well find that we need variety not just as the spice of life — but for life itself. 
Gábor L. Lövei is in the Horticulture and Food Research Institute, Private Bag 11030, Palmerston North, New Zealand.

1. Diamond, J. M. Guns, Germs, and Steel: The Fate of Human Societies (Norton, New York, 1997)

2. Vitousek, P. M., D’Antonio, C. M., Loope, L. D., Rejmánek, M. \& Westbrooks, R. NZ J. Ecol. 21, 1-16 (1997).
3. Campbell, F. T. \& Schlarbaum, S. E. Fading Forests: North American Trees and the Threat of Exotic Pests (Nat. Res. Defense Council, New York, 1994).

4. Wilson, K.-J. Pacific Cons. Biol. (in the press).

5. King, C. M. (ed.) Handbook of New Zealand Mammals (Oxford Univ. Press, 1990)

6. Wright, D. H. Int. J. Biometeorol. 331, 293-299 (1987).

\section{Unwanted and wanted sound}

\section{Thomas D. Rossing}

$\mathrm{M}$ ore and more people are becoming concerned about the control of environmental noise. That was certainly true of those attending the joint meeting of the Acoustical Society of America and the Institute of Noise Control Engineering in June*. Although the meeting included more than 100 sessions covering all aspects of acoustics, noise control received particular attention - especially active control of noise and vibration.

In active noise control, a controlled source is used to cancel out an unwanted sound or vibration. It may employ either feedback or feedforward control (C. Hansen, Adelaide Univ.). In a duct, for example, a basic feedback system uses a microphone and a loudspeaker, along with an electronic controller. The loudspeaker vibrates to cancel out as much of the source sound as possible and to produce a minimum sound level at the error microphone (Fig. 1a). In a basic feedforward system, a reference microphone is added to sample the source noise before it reaches the error microphone (Fig 1b). Because of their inherent stability, feedforward controllers are generally preferred over feedback controllers. Adaptive logic and other refinements can be added.

Effective noise control often requires the reduction of noise transmission through panels or partitions. In active structural acoustic control, actuators are attached to a panel to change its radiation characteristics. For example, 'smart' foam, with a piezoelectric actuator in between layers of sound-absorbing foam, can reduce sound radiation from vibrating plates (C. Guigou and C. R. Fuller, Virginia Polytechnic Inst.). And a new active interior trim panel can control aircraft noise at low frequency, up to $400 \mathrm{~Hz}$ (S. Sharp, G. Koopmann and W. Chen, Penn State Univ.). The actuator is a small, rigid panel that is driven in a piston-like motion by a moving-coil transducer similar to that of a loudspeaker.

In contrast to these papers on unwanted sound, a special session on loudspeakers dealt with improving the quality of wanted sound. Gabriel Weinreich (Univ. Michigan) has designed and built a loudspeaker with a direc-

${ }^{*}$ 133rd Meeting of the Acoustical Society of America, held jointly with NOISE-CON 97 (National Conference on Noise Control Engineering), Pennsylvania State University, State College, Pennsylvania, USA, 14-20 June 1997. tional radiation pattern that is a strong function of angle and frequency, like a violin's output at frequencies above $850 \mathrm{~Hz}$. This produces the illusion that each note comes from a slightly different direction, confusing the common psychoacoustic cues and endowing the sound with a striking spatial sense like that of a violin, an instrument especially noted for its 'directional tone colour'. Weinreich demonstrated the ability of this loudspeaker to reproduce the sound of a violin and a pipe organ. Conversely, an ear-catching demonstration by Bruce Edgar, using his own voice, showed how a new horn design could be used to remove the sound colorations that plagued many vintage horn systems.

Sound can be 'wanted' for rather different purposes. By recording an incoming sound wave, reversing its time structure and re-emitting it, it can be focused back to its point of origin (this time-reversal technique has precedents in radar and optical technology). Practical time-reversal mirrors consist of large, ultrasonic transducer arrays. They have applications in medicine (to destroy kidney stones, for example) and in nondestructive testing of solids (M. Fink, Univ. Denis Diderot, Paris).

Time-reversal mirrors also have applications in the sea, but here the method is complicated by the fact that the medium is changing with time. Yet two experiments conducted in the Mediterranean Sea in April

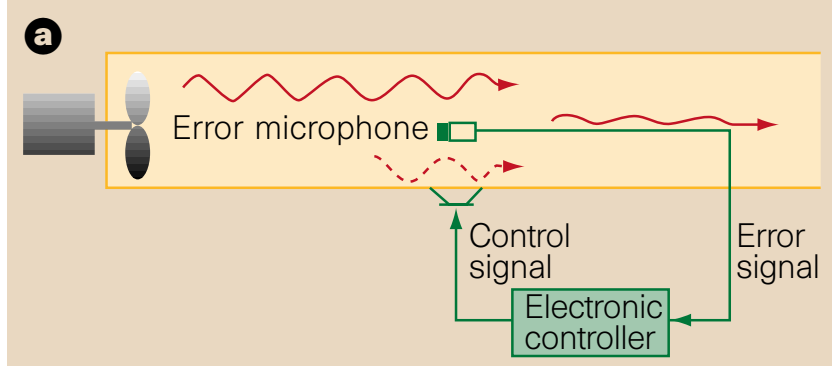

(b

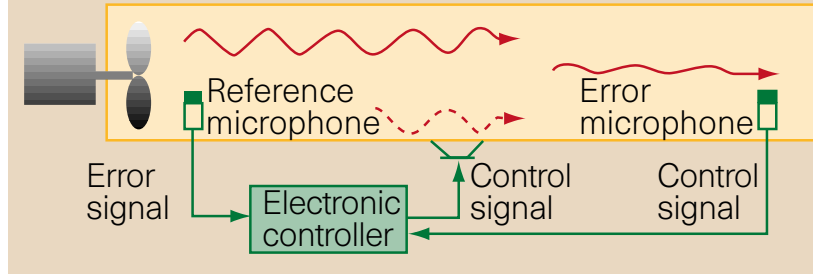

1996 and May 1997 demonstrated that an acoustic time-reversal mirror can focus sound back to its origin even in an inhomogeneous ocean. William Kuperman (Scripps Instn, San Diego) and colleagues used 20 sources and 20 receivers in a vertical array 77 $\mathrm{m}$ across. A source that sent out a 50 -ms ping every two minutes was towed through the focus of the array. The signal was received, reversed and retransmitted successfully to distances as great as $30 \mathrm{~km}$. This experimental result is particularly remarkable when one considers that a spot $1 / 10$ th as deep as the waveguide is projected to a range more than 300 times the depth, with a horizontal extent of about one waveguide depth. These methods can be used to learn more about acoustic propagation in the ocean, perhaps for communications purposes, and to study fluctuations in currents, temperature and salinity using sound as a probe.

Returning to airborne sound of the desirable variety, Judith Brown (Wellesley College and MIT) discussed how to use computers to identify the sounds of musical instruments. The most successful schemes for identifying human speakers rely on the formant structure of speech sounds. (Formants are resonances of the vocal tract that determine speech sounds. Each vowel sound, for example, is characterized by three to five formant frequencies.) Identifying the formants of each speaker allows a computer to distinguish speakers through pattern recognition.

So Brown followed the same procedure for the oboe and saxophone. It turns out that a computer can do very well - in fact, it scored considerably better than humans in identifying oboe sounds, although in the case of saxophones there was little difference. So, as well as doing clever things with sound production, some automatic systems can appreciate the result for us.

Thomas D. Rossing is in the Department of Physics, Northern Illinois University, DeKalb, Illinois 601150-2854, USA.

Figure 1 Two schemes for active noise control. a, Simple feedback, in which the control signal is tweaked to cancel out the unwanted noise; $b$, 'feedforward', in which a second microphone samples the noise, giving a rough value for the control signal directly, and so avoiding the instabilities of simple feedback. 